\title{
A new CF-IRMS system for quantifying stable isotopes of carbon monoxide from ice cores and small air samples
}

\author{
Z. Wang and J. E. Mak \\ Institute for Terrestrial and Planetary Atmospheres, School of Marine and Atmospheric Sciences, Stony Brook University, \\ Stony Brook, NY, USA
}

Received: 26 June 2009 - Published in Atmos. Meas. Tech. Discuss.: 21 October 2009

Revised: 21 July 2010 - Accepted: 1 September 2010 - Published: 5 October 2010

\begin{abstract}
We present a new analysis technique for stable isotope ratios $\left(\delta^{13} \mathrm{C}\right.$ and $\left.\delta^{18} \mathrm{O}\right)$ of atmospheric carbon monoxide (CO) from ice core samples. The technique is an online cryogenic vacuum extraction followed by continuous-flow isotope ratio mass spectrometry (CF-IRMS); it can also be used with small air samples. The CO extraction system includes two multi-loop cryogenic cleanup traps, a chemical oxidant for oxidation to $\mathrm{CO}_{2}$, a cryogenic collection trap, a cryofocusing unit, gas chromatography purification, and subsequent injection into a Finnigan Delta Plus IRMS. Analytical precision of $0.2 \% \circ( \pm 1 \sigma)$ for $\delta^{13} \mathrm{C}$ and $0.6 \% \circ( \pm 1 \sigma)$ for $\delta^{18} \mathrm{O}$ can be obtained for $100 \mathrm{~mL}$ (STP) air samples with $\mathrm{CO}$ mixing ratios ranging from $60 \mathrm{ppbv}$ to $140 \mathrm{ppbv}(\sim 268-$ 625 pmol CO). Six South Pole ice core samples from depths ranging from $133 \mathrm{~m}$ to $177 \mathrm{~m}$ were processed for $\mathrm{CO}$ isotope analysis after wet extraction. To our knowledge, this is the first measurement of stable isotopes of $\mathrm{CO}$ in ice core air.
\end{abstract}

\section{Introduction}

Atmospheric CO plays a key role in global atmospheric chemistry as the main sink for hydroxyl radicals $(\mathrm{OH})$, therefore, strongly affecting the oxidizing capacity of the atmosphere (Crutzen and Zimmermann, 1991; Logan et al., 1981; Thompson, 1992). The major sources of CO in the modern atmosphere are known (Seiler, 1974). Different sources producing atmospheric $\mathrm{CO}$ with distinct ratios of ${ }^{13} \mathrm{C} /{ }^{12} \mathrm{C}$ and ${ }^{18} \mathrm{O} /{ }^{16} \mathrm{O}$ have been observed (Kato et al., 1999a, b; Stevens et al., 1972; Stevens and Wagner, 1989; Brenninkmeijer and Rockmann, 1997). Stable isotope ratios $\left(\delta^{13} \mathrm{C}\right.$ and $\left.\delta^{18} \mathrm{O}\right)$ in atmospheric $\mathrm{CO}$ help to resolve the contributions of certain sources and, thus, to better estimate

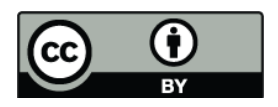

Correspondence to: Z. Wang

(zhihui.wang@stonybrook.edu) the global CO budget (Mak and Kra, 1999; Rockmann et al., 2002; Manning et al., 1997). The CO budget calculated by three-dimensional inverse modelling is more robust with stable isotope $\left({ }^{13} \mathrm{C}\right.$ and $\left.{ }^{18} \mathrm{O}\right)$ data than with $\mathrm{CO}$ mixing ratios alone (Bergamaschi et al., 2000a; Bergamaschi et al., 2000b). But essentially no observations exist to provide information about relative source strengths during preindustrial times. The stable isotopes from air bubbles trapped in ice cores provide information on $\mathrm{CO}$ source strengths in the past. The typical volume of air trapped in ice cores is around $100 \mathrm{~mL}$ (STP) per $\mathrm{kg}$ of ice, and the $\mathrm{CO}$ mixing ratio in Antarctic ice cores is only 50 ppbv (Haan et al., 1996; Haan and Raynaud, 1998). The amount of CO trapped in $1 \mathrm{~kg}$ ice is only around $0.2 \mathrm{nmol}$. The sample size requirements for a conventional dual inlet method are mostly determined by the minimum operating pressure needed to generate a reasonable current at the collector end, which is in the order of $0.1 \mu \mathrm{mol}$ (Merritt and Hayes, 1994). Therefore, the limited sample size of ice core air makes measuring $\mathrm{CO}$ isotope composition challenging.

Continuous-flow isotope ratio mass spectrometry (CFIRMS) systems allow the analysis of small volumes. They have been developed to measure atmospheric $\mathrm{CH}_{4}$ (Rice et al., 2001; Merritt et al., 1995; Lowe et al., 1991), atmospheric $\mathrm{N}_{2} \mathrm{O}$ (Rockmann et al., 2003), atmospheric $\mathrm{H}_{2}$ (Rhee et al., 2004) and volatile organic compounds (VOC) in ambient air (Rudolph et al., 1997). CF-IRMS was first demonstrated by Mak and Yang (1998) for CO isotope analysis by monitoring the relative abundances of masses 44,45 , and 46 of $\mathrm{CO}$ derived $\mathrm{CO}_{2}$. A recent study by Tsunogai et al. (2002) has shown the advantage of isotope analysis for atmospheric $\mathrm{CO}$ using CF-IRMS by simultaneously monitoring the $\mathrm{CO}^{+}$ ion currents at masses 28, 29, and 30. However, preparing $\mathrm{CO}$ standard gas with known isotope ratios and purifying $\mathrm{CO}$ presents different challenges. Because high precision mass spectrometry is usually based on $\mathrm{CO}_{2}$ (Brenninkmeijer, 1999), in the present study we use the technique

Published by Copernicus Publications on behalf of the European Geosciences Union. 


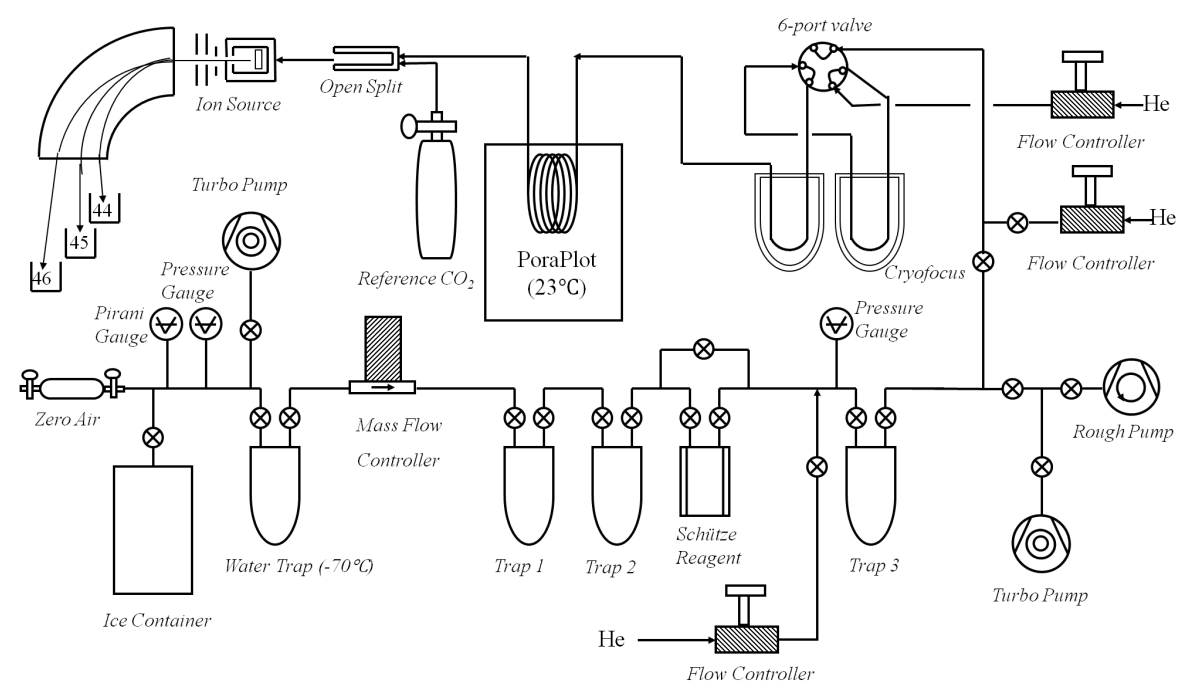

Fig. 1. A schematic diagram of the system used for mixing ratio, $\delta^{13} \mathrm{C}$ and $\delta^{18} \mathrm{O}$ analysis of atmospheric $\mathrm{CO}$ and ice core CO. See details in the text.

of oxidizing $\mathrm{CO}$ to $\mathrm{CO}_{2}$ (Brenninkmeijer, 1993; Stevens and Krout, 1972). Here we present a new cryogenic vacuum extraction system designed to analyse isotope ratios of $\mathrm{CO}$ for small air samples ( 268-625 pmol CO). We use this new system to measure isotope ratios of $\mathrm{CO}$ in air bubbles trapped in Antarctic ice cores.

\section{Methodology}

\subsection{Instrumentation and procedure}

A schematic diagram of the online extraction and preconcentration method for carbon and oxygen isotope analysis of ice core $\mathrm{CO}$ is shown in Fig. 1. A wet extraction system for ice cores is combined with a cryogenic vacuum system for $\mathrm{CO}$ extraction. The cryogenic vacuum extraction system and a stripped down commercially available Finnigan Preconcentration unit is attached to a Finnigan Delta Plus IRMS through a customized open split. The cryogenic vacuum extraction system includes dual four-loop glass coil (1/8 inch ID) cryogenic cleanup traps held at liquid nitrogen temperature, a Schütze reactor (1/8 inch ID U tube, $15 \mathrm{~cm}$ long) and a four loop-glass $\mathrm{CO}_{2}$ collection trap held at liquid nitrogen temperature.

Ambient air samples are attached to the inlet of the cryogenic vacuum extraction system. The air passes through the cryogenic cleanup traps with a flow rate of $50 \mathrm{~mL} / \mathrm{min}$ and atmospheric $\mathrm{CO}_{2}, \mathrm{H}_{2} \mathrm{O}, \mathrm{N}_{2} \mathrm{O}$ and other condensable species are removed due to condensation at liquid nitrogen temperature (Brenninkmeijer, 1993). The purified CO is then selectively and quantitatively oxidized to $\mathrm{CO}_{2}$ by the Schütze reagent, retaining the original oxygen atom of $\mathrm{CO}$ (Brenninkmeijer, 1993). The Schütze reagent is prepared using a slightly modified procedure than described in previous studies, in which the $\mathrm{I}_{2} \mathrm{O}_{5} / \mathrm{H}_{2} \mathrm{SO}_{4}$ on silica gel is flushed with ultrapure dry air flow instead of pumping during the baking process (Schütze, 1949; Smiley, 1965). A bypass is installed for the Schütze reactor tube so that the efficiency of $\mathrm{CO}_{2}$ removal can be evaluated. The bypass also allows continuous back-flushing of the system with ultrapure helium between sample conversions.

The CO-derived $\mathrm{CO}_{2}$ collected in trap 3 is eluted with cryogenically purified ultrapure helium at a flow rate of $40 \mathrm{~mL} / \mathrm{min}$ for $5 \mathrm{~min}$, then cryogenically focused in a microvolume trap of the modified Finnigan preconcentration unit through a Valco six-port valve (Fig. 1). The cryofocus trap is then heated to room temperature and the $\mathrm{CO}_{2}$ is loaded on the gas chromatographic column (Chrompack PoraPLOT Q, $25 \mathrm{~m} \times 0.25 \mathrm{~mm}$ ) at a helium flow of $1 \mathrm{~mL} / \mathrm{min}$ provided by the back inlet of the gas chromatographer. The derived $\mathrm{CO}_{2}$ then passes through an open split into the Finnigan Delta Plus isotope ratio mass spectrometer (IRMS) at a flow rate of about $0.4 \mathrm{~mL} / \mathrm{min}$. The mass spectrometer reference $\mathrm{CO}_{2}$ (Fig. 1) is a certified reference calibrated relative to the internationally accepted IAEA primary standard $\left(\delta^{13} \mathrm{C}\right.$ of $-40.73 \%$ PDB and a $\delta^{18} \mathrm{O}$ of $10.39 \%$ VSMOW, Oztech Trading Corporation, Safford, AZ).

The detailed calculation of $\delta^{13} \mathrm{C}$ and $\delta^{18} \mathrm{O}$ is based on the two observable ion-current ratios (45/44 and 46/44; Santrock et al., 1985) $\delta^{13} \mathrm{C}$ of the original $\mathrm{CO}$ is determined by the $\delta^{13} \mathrm{C}$ of derived $\mathrm{CO}_{2}$, whereas $\delta^{18} \mathrm{O}$ is based on a calibration gas (Brenninkmeijer, 1993). The mixing ratio of $\mathrm{CO}$ for an air sample is determined by the ratio of peak areas between the sample and a calibration gas. 
The online wet extraction line for South Pole ice core samples is also shown in Fig. 1. The ice container is a $1.2 \mathrm{~L}$ borosilicate glass cylindrical container (100 mm ID) with a glass flange (100 mm ID), Viton o-ring (size 348) and external horseshoe clamp. The original part is from Chemglass Life Sciences (Vineland, NJ) and is modified by Universal Instrument Company, Palatine, IL. A four-loop coil trap (1/8 inch ID) with a volume of $15 \mathrm{~mL}$ is made of borosilicate glass and has both sides equipped with hi-vacuum stopcocks and Viton o-rings. The trap held at $-70^{\circ} \mathrm{C}$ lies between the ice container and the inlet of the cryogenic vacuum system and is used to remove water vapour. Upon melting, the air sample released from ice core samples is then processed and analysed with the CF-IRMS method.

\section{Diagnostic experiments}

Diagnostic experiments conducted on the cryogenic extraction system include system blank tests, reproducibility tests, and accuracy tests. The system blank refers to the background signal from the entire analysis system including the background signal from Schütze reagent (Schütze blank) and from ice preparation and extraction (ice blank). The air sample signal is corrected by subtraction of the Schütze blank, therefore, the measurement of the Schütze blank is crucial for the correction of sample signals. While the origin of the Schütze blank is not clear, it is likely that impurities from the ingredients used to make the reagent are responsible for the majority of the blank signal. Another possibility is outgassing from the Viton o-rings, however, after three years of use the blank signal has not changed more than $10 \%$. All Viton o-rings were originally baked out at $130{ }^{\circ} \mathrm{C}$ for $24 \mathrm{~h}$ after which the blank was unchanged. For ice core measurement, besides Schütze blank, there is another source of blank from ice preparation and extraction, which is called ice blank in this study. The sum of these two blanks is system blank for ice core measurement and will be applied to ice core sample correction, thus, the measurement of the system blank is crucial for the correction of ice core sample signals.

To quantify the Schütze blank signal, a flow of zero air devoid of any $\mathrm{CO}$ was processed through the reagent. Zero air was generated by passing ambient air through a platinum catalyst heated to $200^{\circ} \mathrm{C}$ followed by a molecular sieve trap to remove the remaining $\mathrm{CO}_{2}, \mathrm{H}_{2} \mathrm{O}, \mathrm{N}_{2} \mathrm{O}$ and non-methane hydrocarbons (Mak, 1992). The ice blank is determined using artificial bubble-free ice from Laboratoire de Glaciologie et Géophysique de l'Environnement (LGGE), Grenoble, France. A calibration gas is loaded into the ice container after ice is evacuated and mimics the air released from ice core samples. The other procedure to process bubble-free ice is the same as analysing ice core samples which will be discussed in the ice core introduction section. The accuracy and reproducibility of data on stable carbon and oxygen isotopes were determined using a calibration gas with a known isotope ratio as well as field air samples which will be described below.

\section{Calibration gas test}

Experiments were periodically performed to determine the accuracy and reproducibility of stable $\mathrm{C}$ and $\mathrm{O}$ isotope data using a calibration gas. The calibration gas, which is called secondary calibration gas in the present study, was CO mixed with ultrapure air, stored in an electropolished aluminum cylinder (Scott-Marrin, Inc, Riverside, CA) with an initial pressure of $1500 \mathrm{psi}$. The secondary calibration gas was first analysed using a conventional offline extraction (Mak et al., 1994) followed by dual inlet microvolume analysis with Finnigan Delta Plus IRMS (Brenninkmeijer, 1993; Mak and Brenninkmeijer, 1994). CO concentration was measured volumetrically by the conventional offline method (Mak and Brenninkmeijer, 1994) and $\delta^{13} \mathrm{C}$ was measured with the dual inlet method (Brenninkmeijer, 1993; Mak and Brenninkmeijer, 1994).

A primary calibration gas (Scott-Marrin) is routinely processed using the offline method (Mak and Brenninkmeijer, 1994) to evaluate the performance of the offline extraction method and provides $\delta^{18} \mathrm{O}$ of its Schütze reagent. The primary calibration gas has $\delta^{13} \mathrm{C}$ of $-39.8 \pm 0.1 \%$ VPDB (Mak and Brenninkmeijer, 1994) and $\delta^{18} \mathrm{O}$ of $11.36 \pm 0.3 \%$ VSMOW (C. Brenninkmeijer, personal communication, 2010; Brenninkmeijer, 1993). $\delta^{18} \mathrm{O}$ of $\mathrm{CO}$ in the secondary calibration gas was retrieved based on the primary calibration gas measurements (Mak and Kra, 1999; Mak et al., 2003) according to the following equation:

$\delta^{18} \mathrm{O}$ (permil, VSMOW) 2 nd CalCO $=2 \delta^{18} \mathrm{O}_{2 \text { nd } \mathrm{CalCO}_{2}}$ $-\left(2 \delta^{18} \mathrm{O}_{1 \text { st } \mathrm{CalCO}_{2}}-\delta^{18} \mathrm{O}_{1 \mathrm{st} \mathrm{Cal} \mathrm{CO}}\right)$

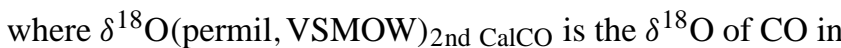

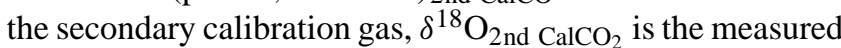
$\delta^{18} \mathrm{O}$ of $\mathrm{CO}_{2}$ derived from the secondary calibration gas, $\delta^{18} \mathrm{O}_{1 \text { st } \mathrm{CalCO}_{2}}$ is the measured $\delta^{18} \mathrm{O}$ of $\mathrm{CO}_{2}$ derived from the primary calibration gas, and $\delta^{18} \mathrm{O}_{1 \text { st } \mathrm{CalCO}}$ is the $\delta^{18} \mathrm{O}$ of $\mathrm{CO}$ in the primary calibration gas (11.36\% VSMOW). The $\delta^{18} \mathrm{O}$ of the secondary calibration gas was, thus, determined by the same procedure as that of a sample, with the exception that the primary calibration was used as a reference, whereas samples were analysed relative to the secondary calibration gas.

The secondary calibration gas was then routinely processed in the new cryogenic extraction system with a flow rate of $50 \mathrm{~mL} / \mathrm{min}$ and a collection time of $2 \mathrm{~min}$ and the following CF-IRMS to evaluate the performance of the new system. The peak area of the secondary calibration gas signal is used to calculate the $\mathrm{CO}$ concentration in field air samples and ice core samples. Since $\delta^{13} \mathrm{C}$ were measured directly 
using the offline method (Brenninkmeijer, 1993; Mak and Brenninkmeijer, 1994) and the new online method independently, $\delta^{13} \mathrm{C}$ measurement between these two methods was used to evaluate the accuracy of the new online method in this study. $\delta^{18} \mathrm{O}$ of the derived $\mathrm{CO}_{2}$ from the secondary calibration gas was used for determining the $\delta^{18} \mathrm{O}$ of the Schütze reagent and retrieving the original $\delta^{18} \mathrm{O}$ of $\mathrm{CO}$ for samples based on the following equation:

$$
\begin{aligned}
& \delta^{18} \mathrm{O}(\text { permil, VSMOW })_{\text {sample }}=2 \delta^{18} \mathrm{O}_{\mathrm{CO}_{2}} \\
& -\left(2 \delta^{18} \mathrm{O}_{2 \text { nd } \mathrm{CalCO}_{2}}-\delta^{18} \mathrm{O}_{2 \text { ndCal CO }}\right)
\end{aligned}
$$

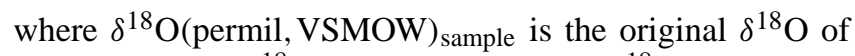
$\mathrm{CO}$ in samples, $\delta^{18} \mathrm{O}_{\mathrm{CO}_{2}}$ is the measured $\delta^{18} \mathrm{O}$ of $\mathrm{CO}_{2}$ derived from sample $\mathrm{CO}, \delta^{18} \mathrm{O}_{\mathrm{Cal} \mathrm{CO}_{2}}$ is the measured $\delta^{18} \mathrm{O}$ of $\mathrm{CO}_{2}$ derived from the $\mathrm{CO}$ in the secondary calibration gas, and $\delta^{18} O_{\mathrm{Cal} C O}$ is the $\delta^{18} \mathrm{O}$ of $\mathrm{CO}$ in the secondary calibration gas, which is determined by Eq. (1). The reproducibility of $\delta^{13} \mathrm{C}$ and $\delta^{18} \mathrm{O}$ of the replicates of secondary calibration gas analysed using the new online method was used to evaluate the precision of the method.

\section{Field sample measurement}

Air samples with the whole volume in the order of 6001 (STP) were collected into high-pressure aluminum air cylinders from the Mauna Loa Observatory and Westmann Islands, Iceland using a previously published protocol (Mak and Brenninkmeijer, 1998). These field samples were first processed with offline extraction and analysed with the conventional dual inlet-microvolume method, by which several hundred litres of the samples were processed. Aliquots of the samples were then processed with the new cryogenic extraction line with $50 \mathrm{~mL} / \mathrm{min}$ flow rate and 2 min collection time and analysed by the following CF-IRMS. 4 to 12 replicates were measured for each sample to give the analytical reproducibility of $\mathrm{CO}$ concentration, $\delta^{13} \mathrm{C}$, and $\delta^{18} \mathrm{O}$ using this new method. $\mathrm{CO}$ concentration was calculated using the following equation:

$$
\mathrm{C}_{\mathrm{S}}=\mathrm{C}_{\mathrm{C}} \cdot \mathrm{V}_{\mathrm{C}} / \mathrm{V}_{\mathrm{S}} \cdot\left(\mathrm{PA}_{\mathrm{S}}-\mathrm{PA}_{\mathrm{B}}\right) /\left(\mathrm{PA}_{\mathrm{C}}-\mathrm{PA}_{\mathrm{B}}\right)
$$

where $\mathrm{C}_{\mathrm{S}}$ is the $\mathrm{CO}$ concentration of a field sample, $\mathrm{C}_{\mathrm{C}}$ is the $\mathrm{CO}$ concentration of the secondary calibration gas, $\mathrm{V}_{\mathrm{C}}$ is the volume of the secondary calibration gas, $\mathrm{V}_{\mathrm{S}}$ is the volume of a field sample, $P A_{S}$ is the raw peak area of a field air sample $\mathrm{CO}, \mathrm{PA}_{\mathrm{B}}$ is the peak area of the Schütze blank, and $\mathrm{PA}_{\mathrm{C}}$ is the raw peak area of the calibration gas according to a volume of $\mathrm{V}_{\mathrm{C}}$. A mass balance calculation based on the peak area and isotope ratios of both the Schütze blank peak and sample peak was applied to subtract the blank signal from the sample signal. The isotope ratios of a field air sample were calculated using the following equation:

$\delta=\left(\delta_{\mathrm{S}} \cdot \mathrm{PA}_{\mathrm{S}}-\delta_{\mathrm{B}} \cdot \mathrm{PA} \mathrm{B}\right) /\left(\mathrm{PA}_{\mathrm{S}}-\mathrm{PA}_{\mathrm{B}}\right)$ where $\delta$ is the $\delta^{13} \mathrm{C}$ or $\delta^{18} \mathrm{O}$ of a field sample, $\delta_{\mathrm{S}}$ is the $\delta^{13} \mathrm{C}$ or $\delta^{18} \mathrm{O}$ of the measurement value, $\delta_{\mathrm{B}}$ is the $\delta^{13} \mathrm{C}$ or $\delta^{18} \mathrm{O}$ of the Schütze blank, $\mathrm{PA}_{\mathrm{S}}$ is the peak area of a field air sample, $\mathrm{PA}_{\mathrm{B}}$ is the peak area of the Schütze blank. Here the flow rate and collection time of the runs for field sample, calibration gas, and Schütze blank is $50 \mathrm{~mL} / \mathrm{min}$ and $2 \mathrm{~min}$.

The measurements of $\mathrm{CO}$ concentration, $\delta^{13} \mathrm{C}$, and $\delta^{18} \mathrm{O}$ with the new online continuous flow method were compared with those using the offline extraction and dual inlet method (Brenninkmeijer, 1993; Mak and Brenninkmeijer, 1994). The primary calibration gas was analysed using the conventional dual inlet method to evaluate the accuracy and showed no bias (Mak and Brenninkmeijer, 1994). The field samples were measured by these two methods independently. $\mathrm{CO}$ concentration measurement using the offline method was determined by manometry of the CO-derived $\mathrm{CO}_{2}$ and the volume of displaced air, whereas that using the new online method was determined by ratio of peak area (Eq. 3). $\delta^{13} \mathrm{C}$ measurement using the offline method was determined by dual inlet analysis, whereas that using the new online method was determined by CF-IRMS and Eq. (4). $\delta^{18} \mathrm{O}$ measurement using the offline method was determined by dual inlet analysis and the primary calibration gas measurements, whereas that using the new online method was determined by CF-IRMS and the secondary calibration measurements. Therefore, the differences of the measurements between these two methods reflect the accuracy of the new online method.

\section{Ice core introduction}

South Pole ice core samples were provided by the US National Ice Core Laboratory (NICL), Boulder, Colorado. They were dry drilled by Jihong Cole-Dai and his colleagues in 2004 at South Pole $\left(89^{\circ} 57^{\prime} \mathrm{S} 17^{\circ} 36^{\prime} \mathrm{W}\right)$. They contain negligible contamination since no kerosene fluid was used for drilling. The ice core samples were semi-cylindrical with an average length of $17 \mathrm{~cm}$ and radius of $5 \mathrm{~cm}$ and were prepared for analysis in a cold room held at $-20^{\circ} \mathrm{C}$. The ice core samples were first trimmed with a band saw to remove around $5 \mathrm{~mm}$ of surface and then scraped with a stainless steel disposable scalpel to remove an additional 1-2 $\mathrm{mm}$ of surface. The ice core sample was weighed and then sealed in a previously prepared container that had been thoroughly cleaned with acetone, rinsed three times with Milli-Q water and heated overnight at $90^{\circ} \mathrm{C}$. The sealed container was then immersed in a cooling bath held at $-20^{\circ} \mathrm{C}$. A $1 / 4^{\prime \prime}$ glass multiloop water trap between the container and the inlet of the cryogenic vacuum extraction system was held at $-70^{\circ} \mathrm{C}$. The ice and container were evacuated and flushed with zero air three times for $10 \mathrm{~min}$. Then the ice was melted by placing the container in a water bath held at a temperature of $60-70^{\circ} \mathrm{C}$. The melting takes around $25 \mathrm{~min}$. After 
melting, the air extracted from the ice was processed through the cryogenic vacuum extraction system and loaded into the CF-IRMS.

As the $\sim 1 \mathrm{~kg}$ ice core sample melted, $\sim 100 \mathrm{~mL}$ (STP) air sample was released, giving an initial pressure in the headspace of the ice container about 300 mbar. During ice core air extraction, the mass flow controller (MFC, Fig. 1) causes a flow restriction due to a lack in pressure difference across the MFC, resulting in a long ice processing time. However, for regular field air sample and routine calibration measurements, a MFC is required to control the flow and to quantify the volume of air processed. The headspace pressure drops to $60 \mathrm{mbar}$ after the air sample was processed for $5 \mathrm{~min}$, at which time a $150 \mathrm{~mL}$ glass flask filled with zero air was expanded into the ice container to build up pressure to around $500 \mathrm{mbar}$. The mixed air was processed for another $5 \mathrm{~min}$. The total processing time is $10 \mathrm{~min}$. The ratio of final pressure to the initial pressure of each step shows how much sample remains in the container. The total percentage of the original air processed for the two steps is calculated according to the following equation:

$\mathrm{P}=1-\mathrm{P} 2 / \mathrm{P} 1 \cdot \mathrm{P} 4 / \mathrm{P} 3$

where $\mathrm{P}$ is the total percentage of the original air processed, $\mathrm{P} 1$ is the initial headspace pressure after air released from ice, $\mathrm{P} 2$ is the pressure after $5 \mathrm{~min}$ processing, $\mathrm{P} 3$ is the pressure after loading zero air, and $\mathrm{P} 4$ is the final pressure after $10 \mathrm{~min}$ processing. Temperature of water in the ice container is close to $0^{\circ}$ after ice melts. The pressure measurements were corrected for saturated water vapour pressure at this temperature (6.1 mbar) (Murphy and Koop, 2005). The percentage of the original air processed is calculated to be around $95 \%$. The flow rate signal of the MFC during the extraction is monitored by a data acquisition device (Labjack Corporation, Lakewood, CO) and Labview program. The volume of air processed for each step is, thus, integrated by the real time flow rate data. The total volume of the released air sample processed is determined by the pressure and the integrated volume based on real time flow rate based on the following equation:

$\mathrm{V}_{\mathrm{S}}=\mathrm{V} 1+\mathrm{V} 2 \cdot \mathrm{P} 2 / \mathrm{P} 3$

where $V_{S}$ is the total volume of air processed for the ice core sample, V1 is the integrated volume for $5 \mathrm{~min}$ extraction, V2 is integrated volume for the second $5 \mathrm{~min}$ extraction, and $\mathrm{P} 2$ and $\mathrm{P} 3$ are the same as above. $\mathrm{CO}$ concentration of ice core samples is then calculated according to Eqs. (6) and (3), with system blank subtracted from sample signal. Based on this volume calculation, the water vapour pressure (6.1 mbar) only causes a $2 \%$ difference. Isotope ratios were calculated according to Eq. (4). Uncertainties for ice core measurements include both the analysis reproducibility and the error propagation of calculations.

\section{Results and discussion}

\subsection{System blank}

The Schütze blank was measured to be lower than $40 \mathrm{pmol} \mathrm{CO}$ (9 ppbv at STP) for a $100 \mathrm{~mL}$ air sample with a flow rate of $50 \mathrm{~mL} / \mathrm{min}$ and a collection time of $2 \mathrm{~min}$. The relationship between Schütze blank and collection time was studied. The Schütze blank signal was observed to be dependent on the collection time and was measured to be $72 \pm 3 \mathrm{pmolCO}(16.1 \pm 0.7 \mathrm{ppbv}$ at STP for a $100 \mathrm{~mL}$ air sample) for a collection time of $10 \mathrm{~min}$ and a flow rate of $50 \mathrm{~mL} / \mathrm{min}$ (Table 1). A linear relationship was found between Schütze blank signal and collection time: $\mathrm{C}=3.84 \cdot t+30.8$, where $\mathrm{C}$ is the Schütze blank signal and $t$ is the collection time. Schütze blank increases with collection time, indicating one unknown contribution to the background is time dependent. The intercept shows a large portion of the blank is time independent, which might be from the Schütze and has not decreased significantly for two years. The relationship between Schütze blank and flow rate has also been studied and measurements are shown in Table 2. With a collection time of $2 \mathrm{~min}$ or $10 \mathrm{~min}$, the Schütze blank signal showed independence of flow rate between $10 \mathrm{~mL} / \mathrm{min}$ and $100 \mathrm{~mL} / \mathrm{min}$.

The $\delta^{13} \mathrm{C}$ and $\delta^{18} \mathrm{O}$ for all the Schütze blank results (Tables 1 and 2 ) is $-15.2 \pm 0.3 \%$ and $33.6 \pm 0.4 \%$, respectively. The isotope ratios of the Schütze blank were independent on collection time, sample size and flow rate. The Schütze blank signal was also found to be independent of the amount of zero air since the $\mathrm{CO}$ in zero air was estimated to be smaller than 1 ppbv based on an offline extraction method (Mak and Brenninkmeijer, 1994).

The ice core analysis system blank includes the total amount of Schütze blank and ice blank. The former was determined to be $72 \pm 2$ pmol for a collection time of $10 \mathrm{~min}$ (Table 2). The system blank was determined using artificial bubble-free ice and the secondary calibration gas. The system blank $\mathrm{CO}$ concentration was taken as difference between the measured $\mathrm{CO}$ concentration for calibration with bubblefree ice and the $\mathrm{CO}$ concentration of secondary calibration gas. The system blank $\mathrm{CO}$ concentration was calculated with the following equation:

$\mathrm{C}_{\mathrm{B}}=\mathrm{C}_{\mathrm{C}} \cdot \mathrm{V}_{\mathrm{C}} / \mathrm{V}_{\mathrm{I}} \cdot \mathrm{PA}_{\mathrm{I}} / \mathrm{PA}_{\mathrm{C}}^{\prime}-\mathrm{C}_{\mathrm{C}}$

where $\mathrm{C}_{\mathrm{B}}$ is the system blank $\mathrm{CO}$ concentration, $\mathrm{C}_{\mathrm{C}}$ is the $\mathrm{CO}$ concentration of the secondary calibration gas, $\mathrm{V}_{\mathrm{C}}$ is the volume of secondary calibration gas, $\mathrm{V}_{\mathrm{I}}$ is the volume of air processed in the bubble-free ice tests and determined by Eq. (6), $P A_{I}$ is the peak area of calibration in ice condition, $\mathrm{PA}^{\prime}{ }_{\mathrm{C}}$ is the peak area of secondary calibration gas according to a volume of $\mathrm{V}_{C}$ and equals to $\mathrm{PA}_{C}-\mathrm{PA}_{\mathrm{B}}$ in Eq. (3). The isotope ratios of system blank were calculated using the following equations:

$\delta=\left(\delta_{\mathrm{I}} \cdot \mathrm{PA}_{\mathrm{I}}-\delta_{\mathrm{C}} \cdot \mathrm{PA}_{\mathrm{C}}^{\prime \prime}\right) /\left(\mathrm{PA}_{\mathrm{I}}-\mathrm{PA}_{\mathrm{C}}^{\prime \prime}\right)$ 
Table 1. Schütze blank of the cryogenic system using zero air at a different collection time and with a flow rate of $50 \mathrm{~mL} / \mathrm{min}$.

\begin{tabular}{ccccc}
\hline $\begin{array}{c}\text { Sample } \\
\text { Volume }(\mathrm{mL})\end{array}$ & $\begin{array}{c}\text { Collection } \\
\text { time }(\mathrm{min})\end{array}$ & $\begin{array}{c}\text { CO blank } \\
(\mathrm{pmol})\end{array}$ & $\begin{array}{c}\delta^{13} \mathrm{C} \\
(\% \circ, \mathrm{VPDB})\end{array}$ & $\begin{array}{c}\delta^{18} \mathrm{O} \\
(\% o, \text { VSMOW })\end{array}$ \\
\hline 100 & 2 & $37 \pm 3$ & $-15.2 \pm 0.3$ & $33.4 \pm 0.3$ \\
250 & 5 & 49 & -15.6 & 33.0 \\
500 & 10 & $72 \pm 3$ & $-15.3 \pm 0.3$ & $33.9 \pm 0.4$ \\
750 & 15 & 89 & -15.3 & 33.9 \\
1500 & 30 & 145 & -15.0 & 33.8 \\
\hline
\end{tabular}

Table 2. Schütze blank of the cryogenic system using zero air at a different flow rate.

\begin{tabular}{cccccc}
\hline $\begin{array}{c}\text { Sample } \\
\text { Volume }(\mathrm{mL})\end{array}$ & $\begin{array}{c}\text { Flow rate } \\
(\mathrm{mL} / \mathrm{min})\end{array}$ & $\begin{array}{c}\text { Collection } \\
\text { time }(\mathrm{min})\end{array}$ & $\begin{array}{c}\mathrm{CO} \text { blank } \\
(\mathrm{pmol})\end{array}$ & $\begin{array}{c}\delta^{13} \mathrm{C} \\
(\% \circ, \mathrm{VPDB})\end{array}$ & $\begin{array}{c}\delta^{18} \mathrm{O} \\
(\% \text { o, VSMOW })\end{array}$ \\
\hline 20 & 10 & 2 & $39 \pm 1$ & $-15.8 \pm 0.3$ & $34.1 \pm 0.4$ \\
50 & 25 & 2 & $36 \pm 0.3$ & $-15 \pm 0.4$ & $33.9 \pm 0.2$ \\
100 & 50 & 2 & $37 \pm 3$ & $-15.2 \pm 0.3$ & $33.4 \pm 0.3$ \\
150 & 75 & 2 & $40 \pm 2$ & $-15.6 \pm 0.4$ & $33.2 \pm 0.5$ \\
200 & 100 & 2 & $40 \pm 2$ & $-15.3 \pm 0.3$ & $33.2 \pm 0.5$ \\
100 & 10 & 10 & 72 & -15.1 & 33.3 \\
250 & 25 & 10 & $72 \pm 5$ & $-15.7 \pm 0.2$ & $33.6 \pm 0.4$ \\
500 & 50 & 10 & $72 \pm 3$ & $-15.3 \pm 0.3$ & $33.9 \pm 0.4$ \\
750 & 75 & 10 & 69 & -15.1 & 34.1 \\
1000 & 100 & 10 & 74 & -15.5 & 33.8 \\
\hline
\end{tabular}

$\mathrm{PA}_{\mathrm{C}}^{\prime \prime}=\mathrm{PA}_{\mathrm{C}}^{\prime} \cdot \mathrm{V}_{\mathrm{I}} / \mathrm{V}_{\mathrm{C}}$

where $\delta$ is the $\delta^{13} \mathrm{C}$ or $\delta^{18} \mathrm{O}$ of system blank, $\delta_{\mathrm{I}}$ is the $\delta^{13} \mathrm{C}$ or $\delta^{18} \mathrm{O}$ of the measurement value, $\delta_{\mathrm{C}}$ is the $\delta^{13} \mathrm{C}$ or $\delta^{18} \mathrm{O}$ of secondary calibration gas, $\mathrm{PA}_{\mathrm{I}}, \mathrm{PA} \mathrm{A}^{\prime} \mathrm{C}$, VI, and $\mathrm{V}_{\mathrm{C}}$ are the same as those in Eq. (7), $\mathrm{PA}^{\prime \prime}{ }_{C}$ is the expected peak area of calibration gas in ice condition according to a volume of $\mathrm{V}_{\mathrm{I}}$.

The long processing time and the concomitant large blank from the Schütze reagent limit the precision of isotope ratios measured using this technique. To shorten the processing time and decrease the Schütze blank, we attempted to use adsorbents such as molecular sieve $5 \mathrm{~A}$ and molecular sieve $13 \mathrm{X}$ held at liquid nitrogen temperature to condense the air released from ice cores. However, the molecular sieves caused isotope fractionation of both carbon (2-3\%o) and oxygen (4\%o), thus, these adsorbents were no longer applied. The use of a Teflon beaker liner (Welch Fluorocarbon Inc.) was also tried, as its volume was adjustable and, thus, could contribute to a buildup of pressure in the headspace by shrinking and pushing water upward. However, the permeability of Teflon for major components of air limited the use of this material. Tedlar (polyvinyl fluoride), another polyfluorocarbon was investigated as a low-permeability substitute for Teflon. The rigidity of Tedlar film made engineering a Tedlar liner quite difficult and gives no real advantage. In the end, while the idea of reducing the size of the Schütze blank is intriguing and may warrant further study, we opted to keep our sampling protocol simple and characterised the Schütze blank to a high degree of precision. For future study, an old fashioned mercury toepler pump could be ideal for solving this problem by reducing extraction time and Schütze blank (Brenninkmeijer, 1983).

An initial high system blank of $200 \mathrm{pmol} \mathrm{CO}$ was thought to be caused by $\mathrm{CO}$ adsorption on the ice surface. The blank decreased significantly to a level of 90 pmol CO after ice and container were evacuated and flushed with zero air three times. Further flushing with zero air did not reduce the system blank further. The bubble-free ice was also tested under light and dark environments to rule out the possibility of photochemical production. The isotope composition $\left(\delta^{13} \mathrm{C}=-15 \%\right.$ o of the system blank and the similar blank signal between light and dark environment indicates that the ice blank is from air diffusion/adsorption - not in situ photochemical production - since $\delta^{13} \mathrm{C}$ of $\mathrm{CO}$ from oxidation processes is much lower (Stevens and Wagner, 1989). The six measurements of system blank are shown in Table 3. The measured system blank is $90 \pm 8 \mathrm{pmol}$. The $\delta^{13} \mathrm{C}$ and $\delta^{18} \mathrm{O}$ of system blank is $-15.3 \pm 0.3 \%$ and $33.4 \pm 0.5 \%$, respectively. The uncertainties in $\mathrm{CO}$ concentration and isotope ratios in system blanks, which will be used for evaluating the uncertainties of ice core samples, are ascribed to random error in preparing bubble-free ice samples. The system blank signal is subtracted from the sample signal by a mass balance calculation. The system blank is crucial for the ice core data since it accounts for $\sim 30 \%$ of the total signal and the CO blank 
Table 3. System blank using calibration gas and artificial bubble-free ice.

\begin{tabular}{|c|c|c|c|c|c|}
\hline Artificial ice sample \# & Artificial ice type & $\begin{array}{l}\text { Weight } \\
(\mathrm{g})\end{array}$ & $\begin{array}{c}\text { CO blank } \\
\text { (pmol) }\end{array}$ & $\begin{array}{c}\delta^{13} \mathrm{C} \\
(\% o, \mathrm{VPDB})\end{array}$ & $\begin{array}{c}\delta^{18} \mathrm{O} \\
(\% \circ, \mathrm{VSMOW})\end{array}$ \\
\hline 1 & Polycrystalline ice & 256 & 90 & -15.4 & 34.0 \\
\hline 2 & Polycrystalline ice & 385 & 99 & -15.3 & 32.9 \\
\hline 3 & Monocrystalline ice & 200 & 77 & -15.6 & 33.6 \\
\hline 4 & Monocrystalline ice ${ }^{(b)}$ & 275 & 90 & -15.0 & 33.3 \\
\hline 5 & Monocrystalline ice & 150 & 99 & -14.9 & 32.9 \\
\hline 6 & Monocrystalline ice & 347 & 86 & -15.3 & 33.7 \\
\hline
\end{tabular}

Note: ${ }^{(a)}$ : system blank including Schütze blank and ice blank; ${ }^{(b)}$ : Dark test: glass container was wrapped with aluminum foil during the experiment.

Table 4. Comparison of $\delta^{13} \mathrm{C}$ and $\delta^{18} \mathrm{O}$ results of field $\mathrm{CO}$ samples obtained by dual inlet microvolume analysis and online extraction CF-IRMS.

\begin{tabular}{|c|c|c|c|c|c|c|c|c|c|c|c|c|c|c|c|}
\hline \multirow[b]{2}{*}{ Sample ID } & \multicolumn{7}{|c|}{ Dual inlet microvolume analysis } & \multicolumn{8}{|c|}{ On-line extraction CF-IRMS } \\
\hline & $\begin{array}{l}\text { Collection } \\
\text { Date }\end{array}$ & $\begin{array}{c}{[\mathrm{CO}]} \\
(\mathrm{ppbv})\end{array}$ & $\mathrm{SD}^{(\mathrm{a})}$ & $\begin{array}{c}\delta^{13} \mathrm{C} \\
(\%, \mathrm{VPDB})\end{array}$ & $\mathrm{SD}^{(\mathrm{a})}$ & $\begin{array}{c}\delta^{18} \mathrm{O} \\
(\% \circ, \text { VSMOW })\end{array}$ & $\mathrm{SD}^{(\mathrm{a})}$ & $\begin{array}{c}\text { Sample } \\
\text { Volume (L) }\end{array}$ & $\begin{array}{c}{[\mathrm{CO}]} \\
\text { (ppbv) }\end{array}$ & SD & $\begin{array}{c}\delta^{13} \mathrm{C} \\
(\%, \mathrm{VPDB})\end{array}$ & $\mathrm{SD}$ & $\begin{array}{c}\delta^{18} \mathrm{O} \\
(\% \circ, \text { VSMOW) }\end{array}$ & SD & $\begin{array}{c}\text { Sample } \\
\text { Volume (L) }\end{array}$ \\
\hline $315 \mathrm{MLCO}(12)^{(\mathrm{b})}$ & 28-Aug-07 & 61 & 3 & -31.00 & 0.4 & -1.27 & 0.5 & 286 & 62 & 1 & -30.80 & 0.17 & -1.33 & 0.61 & 0.1 \\
\hline $393 \operatorname{ICE}(5)$ & 24-Jan-07 & 126 & 3 & -27.19 & 0.4 & 8.74 & 0.5 & 658 & 125 & 2 & -27.45 & 0.28 & 8.49 & 0.20 & 0.1 \\
\hline $394 \operatorname{ICE}(7)$ & 31-Jan-07 & 128 & 3 & -27.25 & 0.4 & 8.25 & 0.5 & 678 & 124 & 2 & -27.36 & 0.24 & 8.35 & 0.38 & 0.1 \\
\hline 396ICE(4) & 17-Jan-07 & 137 & 3 & -27.63 & 0.4 & 9.16 & 0.5 & 662 & 139 & 1 & -27.84 & 0.19 & 9.39 & 0.36 & 0.1 \\
\hline 397ICE(4) & 07-Feb-07 & 134 & 3 & -27.58 & 0.4 & 8.19 & 0.5 & 602 & 137 & 2 & -27.71 & 0.10 & 8.32 & 0.21 & 0.1 \\
\hline 398ICE(5) & 28-Feb-07 & 139 & 3 & -26.93 & 0.4 & 9.64 & 0.5 & 674 & 144 & 4 & -27.15 & 0.28 & 9.43 & 0.38 & 0.1 \\
\hline
\end{tabular}

Note ${ }^{(a)}$ : this standard deviation $( \pm 1 \sigma)$ for dual inlet includes both analytical error for mass spectrometric analysis and sample preparation error (Mak and Brenninkmeijer, 1994). (b): the number in parentheses next to sample ID is the number of analyses by online extraction CF-IRMS.

applied for each sample. The evaluation of the blank correction to the uncertainty of ice core samples will be discussed later in this paper.

\section{Calibration gas}

The $\mathrm{CO}$ concentration of the secondary calibration gas was measured to be 141 ppbv based on the primary calibration on National Oceanic and Atmospheric Administration/Climate Monitoring and Diagnostics Laboratory (NOAA/CMDL) $\mathrm{CO}$ reference scale. $\delta^{13} \mathrm{C}$ of $\mathrm{CO}$ in the secondary calibration gas was measured to be $-45.56 \%$ VPDB with the dual inlet method by the IRMS. $\delta^{18} \mathrm{O}$ of $\mathrm{CO}$ in the secondary calibration gas was measured to be $2.44 \%$ VSMOW according to Eq. (1). The results of $\delta^{13} \mathrm{C}$ of $\mathrm{CO}$ and $\delta^{18} \mathrm{O}$ of derived $\mathrm{CO}_{2}$ from the secondary calibration gas runs are shown in Fig. 2. The mean value of $\delta^{13} \mathrm{C}$ is $-45.40 \%$ (VPDB) with a standard deviation of $0.33 \% \circ( \pm 1 \sigma)$ for 47 runs with $\mathrm{CO}$ amount ranging from $232 \mathrm{pmol}$ to $4 \mathrm{nmol}$. The mean value of $\delta^{18} \mathrm{O}$ of derived $\mathrm{CO}_{2}$ from the secondary calibration gas is $0.42 \%$ (VSMOW) with a standard deviation of $0.32 \%$ o $( \pm 1 \sigma) . \quad \delta^{13} \mathrm{C}$ shows an offset of $+0.16 \%$, which is smaller than the standard deviation of $0.33 \% \circ( \pm 1 \sigma)$, indicating good performance of the line. This $\delta^{18} \mathrm{O}$ value was used for determining the $\delta^{18} \mathrm{O}$ of $\mathrm{CO}$ for air samples according to Eq. (2).

\section{Field sample measurement}

Measurements of 6 field air samples using the new online extraction CF-IRMS as well as the offline method are shown in Table 4 . With a sample volume of only $0.1 \%$ of that used in the offline method, our new online analysis system still provided comparable precisions for both $\mathrm{CO}$ concentration and isotope ratios as the offline method. For this offline method, $\pm 1 \sigma$ standard deviation of $\mathrm{CO}$ concentration is $3 \mathrm{ppbv}$ with sample preparation errors and for $\delta^{13} \mathrm{C}$ and $\delta^{18} \mathrm{O}$ is $0.4 \%$ and $0.5 \%$, respectively (Mak and Brenninkmeijer, 1994). Analytical precision of $2 \mathrm{ppb}( \pm 1 \sigma)$ for $\mathrm{CO}$ mixing ratio, $0.2 \%$ $( \pm 1 \sigma)$ for $\delta^{13} \mathrm{C}$ and $0.6 \% \circ( \pm 1 \sigma)$ for $\delta^{18} \mathrm{O}$ were obtained for a sample size of $268 \mathrm{pmol} \mathrm{CO}(100 \mathrm{~mL}$ air sample with $\mathrm{CO}$ mixing ratio of $60 \mathrm{ppbv}$ ) from the new online analysis method. Notice that the sample from Mauna Loa can be used to assess the linearity of the system since its isotope ratios are very different from the others (Table 4). Considering the uncertainties, no significant difference for $\mathrm{CO}$ concentration, $\delta^{13} \mathrm{C}$, and $\delta^{18} \mathrm{O}$ was found between the offline dual inlet microvolume analysis and the online extraction CF-IRMS analysis, implying the reliable accuracy of the new online method. 
Table 5. Online extraction CF-IRMS measurements for South Pole ice core CO.

\begin{tabular}{|c|c|c|c|c|c|c|c|c|c|c|c|}
\hline $\begin{array}{r}\text { Sample } \\
\text { Depth (m) }\end{array}$ & $\begin{array}{r}\text { Mean gas } \\
\text { age }(\mathrm{Yr} \mathrm{AD})^{(\mathrm{c})}\end{array}$ & $\begin{array}{r}{[\mathrm{CO}]} \\
\text { (ppbv) }\end{array}$ & $\begin{array}{r}\text { SD } \\
\text { (ppbv) }\end{array}$ & $\begin{array}{r}\delta^{13} \mathrm{C} \\
(\% \circ, \mathrm{VPDB})\end{array}$ & $\begin{array}{r}\text { SD } \\
(\%)\end{array}$ & $\begin{array}{r}\delta^{13} \mathrm{C}^{(\mathrm{d})} \\
(\%, \mathrm{VPDB})\end{array}$ & $\begin{array}{r}\delta^{18} \mathrm{O} \\
(\% \circ, \mathrm{VSMOW})\end{array}$ & $\begin{array}{r}\text { SD } \\
(\% o)\end{array}$ & $\begin{array}{r}\delta^{18} \mathrm{O}^{(\mathrm{d})} \\
(\%, \mathrm{VSMOW})\end{array}$ & $\begin{array}{r}\text { [CO]_blank } \\
\text { (ppbv) }\end{array}$ & $\begin{array}{r}\text { Ice weight } \\
(\mathrm{g})\end{array}$ \\
\hline 135 & $1821 \pm 110$ & 57 & 4 & -28.83 & 0.4 & -29.43 & -1.79 & 1.1 & -2.99 & 22 & 872 \\
\hline 147 & $1688 \pm 110$ & 39 & 4 & -29.40 & 0.4 & -30.00 & -1.89 & 1.1 & -3.09 & 18 & 877 \\
\hline 157 & $1578 \pm 110$ & 37 & 4 & -29.15 & 0.4 & -29.75 & -1.02 & 1.1 & -2.22 & 18 & 918 \\
\hline $165 \mathrm{~T}^{(\mathrm{a})}$ & $1490 \pm 110$ & 42 & 4 & -28.47 & 0.4 & -29.07 & -0.49 & 1.1 & -1.69 & 18 & 922 \\
\hline $165 \mathrm{~B}^{(\mathrm{b})}$ & $1490 \pm 110$ & 46 & 4 & -28.95 & 0.4 & -29.55 & -0.96 & 1.1 & -2.16 & 18 & 957 \\
\hline 177 & $1358 \pm 110$ & 57 & 4 & -27.40 & 0.4 & -28.00 & 1.43 & 1.1 & 0.23 & 22 & 939 \\
\hline
\end{tabular}

Note ${ }^{(a)}: 165 \mathrm{~m}$ top; (b) $165 \mathrm{~m}$ bottom. Standard deviation is based on the results from calibration runs with bubble-free ice processed the same way as that for real ice core samples (c): gas ages are linearly interpolated based on the gas age-depth relationship of South Pole ice core according to (Neftel et al., 1985; Schwander and Stauffer, 1984; Friedli et al., 1984); age errors are calculated according to (Friedli et al., 1984; Neftel et al., 1985; Schwander and Stauffer, 1984). (d): Isotope ratios corrected by gravitational fractionation (Battle et al., 1996; Landais et al., 2006).

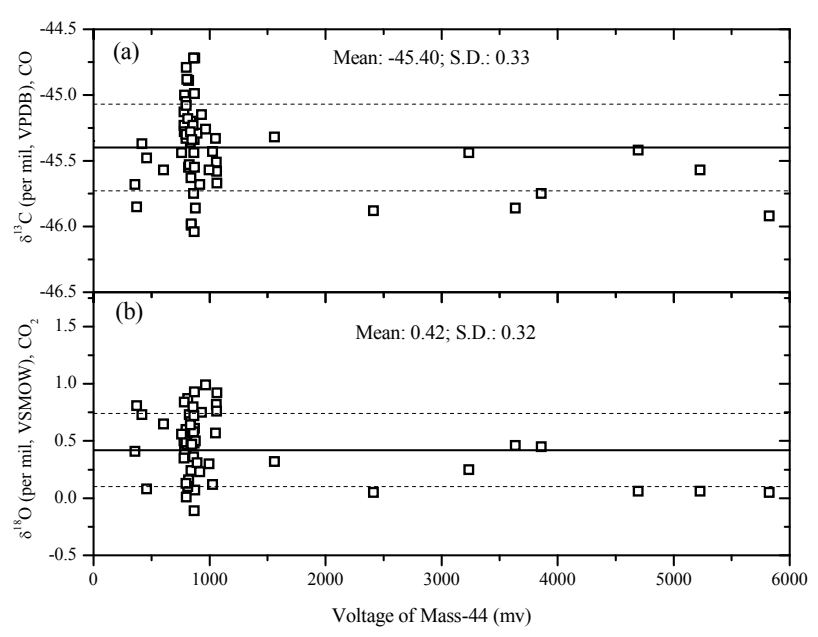

Fig. 2. Measurements of (a) $\delta^{13} \mathrm{C}$ and (b) $\delta^{18} \mathrm{O}$ for calibration gas versus voltage mass-44 ranging from $400 \mathrm{mv}$ to $6 \mathrm{~V}$. Mean value of $\delta^{13} \mathrm{C}(\mathrm{CO})$ : $-45.40 \%$ (with standard deviation $0.33 \%$ ); mean value of $\delta^{18} \mathrm{O}\left(\mathrm{CO}_{2}\right)$ : $0.42 \%$ (with standard deviation $0.32 \%$ ). Sample size is linear with voltage of mass- 44 and 700 pmol CO gives $1 \mathrm{~V}$ for the signal of voltage mass- 44 .

\section{South Pole ice core measurement}

Six ice core samples were measured in this study. Results of the measurements of the 6 South Pole ice core samples, including both $\mathrm{CO}$ mixing ratios and isotope ratios, are shown in Table 5. CO concentration was calculated according to Eqs. (3) and (6), and the isotope ratios were calculated using the above Eq. (4). The system blank specified for each ice core sample (column 11 in Table 5) was the average of system blank before and after the ice core sample. Ice core sample at depths of $135 \mathrm{~m}$ and $177 \mathrm{~m}$ were measured after \#2 artificial ice measurement and before \#5 artificial ice measurement (Table 3), so the average of \#2 and \#5 system blank was specified for these two ice core samples. The other four ice core samples were measured after \#3 artificial ice measurement and before \#6 artificial ice measurement (Table 3), so the average of \#3 and \#6 system blank was specified for the other four ice core samples.

The uncertainties are shown as standard deviations (SD, $\pm 1 \sigma$ ) (Table 5) and calculated according to the error propagation of calculation and the reproducibility of bubble-free ice tests. The contribution of the system blank is as high as $30 \%$ and introduced uncertainties to ice core measurements due to the blank correction. The $3 \mathrm{ppbv}$ uncertainty of $\mathrm{CO}$ concentration for field sample measurement and 9 pmol uncertainty of system blank determined the uncertainty of $\mathrm{CO}$ concentration of ice core samples to be 4 ppbv. According to the uncertainties of $\mathrm{CO}$ concentration $(9 \mathrm{pmol})$ of system blank and Eq. (3), the correction of the blank introduced an uncertainty of $0.4 \%$ or $\delta^{13} \mathrm{C}$ and $1.1 \%$ of $\delta^{18} \mathrm{O}$. According to uncertainties of isotope ratios $\left(0.3\right.$ for $\delta^{13} \mathrm{C}$ and $0.5 \%$ for $\delta^{18} \mathrm{O}$ ) of system blank, the correction introduced an uncertainty of $0.1 \%$ for $\delta^{13} \mathrm{C}$ and $0.2 \%$ for $\delta^{18} \mathrm{O}$. As a result, the uncertainty was calculated to be $0.4 \%$ for $\delta^{13} \mathrm{C}$ and $1.1 \%$ o for $\delta^{18} \mathrm{O}$ for ice core samples. The signal/noise ratios for concentration and isotope ratios were larger than 3, indicating significant change in both $\mathrm{CO}$ concentration and isotope ratios.

The raw data for $\mathrm{CO}$ mixing ratio and isotope ratios shown have been corrected for gravitational fractionation according to the $\delta^{15} \mathrm{~N}$ measurement performed on South Pole firn (Battle et al., 1996; Landais et al., 2006). The gravitational effect for CO can be neglected (Haan and Raynaud, 1998). The isotope ratio corrections for $\delta^{13} \mathrm{C}$ and $\delta^{18} \mathrm{O}$ are $-0.6 \%$ and $-1.2 \%$, respectively (Battle et al., 1996; Landais et al., 2006). The corrected isotope ratios are also shown in Table 5. The consistency of CO mixing ratio and isotope ratios between the duplicate South Pole ice core samples at $165 \mathrm{~m}$ (AD 1490) indicate that the new analytical technique produces consistent results for ice core samples with a $\mathrm{CO}$ amount as low as 223 pmol. 
Present-day observations at Scott Base $\left(77.8^{\circ} \mathrm{S}, 167.5^{\circ} \mathrm{E}\right)$ indicate annual mean $\mathrm{CO}$ concentration is $51 \mathrm{ppbv}$ with $\delta^{13} \mathrm{C}$ and $\delta^{18} \mathrm{O}$ is $-29.4 \%$ VPDB and $-3.8 \%$ VSMOW, respectively for the period 1993-1995 (Brenninkmeijer, 1993; Moss et al., 1998). Thus, CO concentrations at $135 \mathrm{~m}$ (AD 1821) and $177 \mathrm{~m}$ (AD 1358) are comparable with those in modern atmosphere, whereas $\mathrm{CO}$ concentration at $157 \mathrm{~m}$ (AD 1578) is around 20 ppbv lower than that in modern atmosphere. Furthermore, both $\delta^{13} \mathrm{C}$ and $\delta^{18} \mathrm{O}$ of the sample at $177 \mathrm{~m}$ (AD 1358) have a shift of isotope ratio larger than the gravitational fractionation compared with presentday values (Wang, 2009), showing real variations of CO isotope ratios in the past atmosphere.

Based on isotope mass balance calculation (Wang, 2009) and MOZART simulations on present $\mathrm{CO}$ source strengths (K. Park, personal communication, 2010), the $600 \mathrm{ppb}$ of $\left[\mathrm{CH}_{4}\right]$ in 1500 will cause an enrichment of $2.6 \%$ for $\delta^{18} \mathrm{O}$ in $\mathrm{CO}$ and $17 \mathrm{ppbv}$ lower $\mathrm{CO}$ concentration compared with present day. A change of $+50 \%$ biomass burning emission compared with present day's level causes an enrichment of $1.5 \%$ for $\delta^{18} \mathrm{O}$ in $\mathrm{CO}$ and a change of $-50 \%$ biomass burning emission causes a depletion of $1.9 \%$ for $\delta^{18} \mathrm{O}$ in $\mathrm{CO}$. A change of $+50 \%$ NMHC oxidation compared with modern day level causes a depletion of $0.8 \%$ ofor $\delta^{18} \mathrm{O}$ in $\mathrm{CO}$ and a change of $-50 \%$ NMHC oxidation causes an enrichment of $1.0 \%$ ofor $\delta^{18} \mathrm{O}$ in CO. Thus, the $4 \%$ o change of $\delta^{18} \mathrm{O}$ in $\mathrm{CO}$ in our ice core samples allows us to deduce useful information for the $\mathrm{CO}$ source strength in the preindustrial times.

The 20 ppbv variation of $\mathrm{CO}$ concentration indicates the change of the absolute source strength of $\mathrm{CO}$ in the past several centuries, while the $\sim 1.4 \%$ o variation of $\delta^{13} \mathrm{C}$ and $\sim 4 \%$ o of $\delta^{18} \mathrm{O}$ indicates the change of the relative source strength of $\mathrm{CO}$ such as biomass burning emission in the past atmosphere. This combined information allows us to reveal the biogeochemical causes of the variations of atmospheric $\mathrm{CO}$ budget such as variation of biomass burning emission due to the change of aridity/moisture and/or warmer/cooler temperature and the variation of biogenic emission of non-methane hydrocarbon from vegetation due to the change of temperature and vegetation area in the preindustrial times. The drop of $\mathrm{CO}$ concentration and depletion of both ${ }^{13} \mathrm{C}$ and ${ }^{18} \mathrm{O}$ in the 17th and 18th century suggests a drop of biomass burning in this period. $\mathrm{CO}$ from biomass burning in high latitude SH originates from the tropics (Edwards et al., 2006). It has been reported that biomass burning is more favourable with warmer ambient temperatures and dryer conditions (Carcaillet et al., 2002; Crutzen and Andreae, 1990). The suggested drop of biomass burning in this study is consistent with the cooler temperature and moist atmosphere in the tropics during the 17th and 18th century (Thompson et al., 2003; Verschuren et al., 2000), and it is also consistent with the biomass burning reconstruction from sedimentary charcoal record (Marlon et al., 2008).

\section{Conclusions}

Six South Pole ice core samples were analysed with a new technique using online cryogenic extraction and CF-IRMS analysis for simultaneous measurement of stable isotope ratios $\left(\delta^{13} \mathrm{C}\right.$ and $\left.\delta^{18} \mathrm{O}\right)$ of atmospheric $\mathrm{CO}$ in small air samples. The concentrations and isotope ratios provide important information on the source strengths of $\mathrm{CO}$ such as biomass burning emissions in preindustrial times and help to extrapolate the overall stability of tropospheric chemistry basics: $\mathrm{CH}_{4}$-CO-OH cycle. Concentration, $\delta^{13} \mathrm{C}$, and $\delta^{18} \mathrm{O}$ values for atmospheric $\mathrm{CO}$ with sample size as small as $220 \mathrm{pmol}$ can be determined using this new technique with high precision. This new online technique is especially useful in characterising air samples with very small volume, such as atmospheric CO trapped in an ice core. This is to our knowledge the first measurement of $\mathrm{CO}$ isotopes in ice core samples.

Acknowledgements. We thank C. A. M. Brenninkmeijer, Max Planck Institute for Chemistry, Mainz, and J. Chappellaz, Laboratoire de Glaciologie et Géophysique de l'Environnement, CNRS, Grenoble, for useful help and discussions. We also thank Ed Brooke from Oregon State University for providing bubble-free ice and Maurine Montagnat, Laboratoire de Glaciologie et Géophysique de l'Environnement for providing monocrystalline and polycrystalline bubble-free ice. We gratefully thank the Iceland Meteorology Office and in particular Elvar Ástráơsson, Óskar J. Sigurðsson, and Johanna Margret Thorlacius for air sample collection and logistical support. We also thank the NOAA CMDL network for air sample collection and logistical support at Mauna Loa Observatory. South Pole ice core samples were provided by the National Ice Core Laboratory and we greatly thank Mark Twickler for his help in ice allocation. This work was supported by the National Science Foundation grant OCE073406. We thank Andy Matthews from Mt. Sinai High School for providing a walk-in freezer space for preparing ice core samples. Z. Wang most importantly thanks Peter Alpert for spending time to edit this paper.

Edited by: R. Koppmann

\section{References}

Battle, M., Bender, M., Sowers, T., Tans, P. P., Butler, J. H., Elkins, J. W., Ellis, J. T., Conway, T., Zhang, N., Lang, P., and Clarke, A. D.: Atmospheric gas concentrations over the past century measured in air from firn at the South Pole, Nature, 383, 231-235, 1996.

Bergamaschi, P., Hein, R., Brenninkmeijer, C. A. M., and Crutzen, P. J.: Inverse modeling of the global CO cycle 2. Inversion of C13/C-12 and O-18/O-16 isotope ratios, J. Geophys. Res.-Atmos., 105, 1929-1945, 2000a.

Bergamaschi, P., Hein, R., Heimann, M., and Crutzen, P. J.: Inverse modeling of the global $\mathrm{CO}$ cycle 1 . Inversion of $\mathrm{CO}$ mixing ratios, J. Geophys. Res.-Atmos., 105, 1909-1927, 2000b.

Brenninkmeijer, C. A. M.: Deuterum, oxygen-18 and carbon-13 in tree rings and peat depositsin relation to climate, $\mathrm{Ph} . \mathrm{D}$. thesis, Univ. of Groningen, The Netherlands, 1983. 
Brenninkmeijer, C. A. M.: Measurement of the abundance of ${ }^{14} \mathrm{CO}$ in the atmosphere and the ${ }^{13} \mathrm{C} /{ }^{12} \mathrm{C}$ and ${ }^{18} \mathrm{O} /{ }^{16} \mathrm{O}$ ratio of atmospheric CO with applications in New Zealand and Antarctica, J. Geophys. Res, 98, 10595-10614, 1993.

Brenninkmeijer, C. A. M. and Rockmann, T.: Principal factors determining the ${ }^{18} \mathrm{O} /{ }^{16} \mathrm{O}$ ratio of atmospheric $\mathrm{CO}$ as derived from observations in the southern hemispheric troposphere and lowermost stratosphere, J. Geophys. Res.-Atmos., 102, 25477-25485, 1997.

Brenninkmeijer, C. A. M.: Review of progress in isotope studies of atmospheric carbon monoxide, Chemosphere-Global Change Science, 1, 33-52, 1999.

Carcaillet, C., Almquist, H., Asnong, H., Bradshaw, R. H. W., Carrion, J. S., Gaillard, M. J., Gajewski, K., Haas, J. N., Haberle, S. G., Hadorn, P., Muller, S. D., Richard, P. J. H., Richoz, I., Rosch, M., Goni, M. F. S., von Stedingk, H., Stevenson, A. C., Talon, B., Tardy, C., Tinner, W., Tryterud, E., Wick, L., and Willis, K. J.: Holocene biomass burning and global dynamics of the carbon cycle, Chemosphere, 49, 845-863, 2002.

Crutzen, P. J. and Andreae, M. O.: Biomass burning in the tropics: impact on atmospheric chemistry and biogeochemical cycles, Science, 250, 1669-1678, 1990.

Crutzen, P. J. and Zimmermann, P. H.: The changing photochemistry of the troposphere, Tellus A, 43, 136-151, 1991.

Edwards, D. P., Emmons, L. K., Gille, J. C., Chu, A., Attie, J. L., Giglio, L., Wood, S. W., Haywood, J., Deeter, M. N., Massie, S. T., Ziskin, D. C., and Drummond, J. R.: Satellite-observed pollution from Southern Hemisphere biomass burning, J. Geophys. Res.-Atmos., 111, D14312, doi:10.1029/2005jd006655, 2006.

Friedli, H., Moor, E., Oeschger, H., Siegenthaler, U., and Stauffer, B.: ${ }^{13} \mathrm{C} /{ }^{12} \mathrm{C}$ Ratios in $\mathrm{CO}_{2}$ Extracted from Antarctic Ice, Geophys. Res. Lett., 11, 1145-1148, 1984.

Haan, D., Martinerie, P., and Raynaud, D.: Ice core data of atmospheric carbon monoxide over Antarctica and Greenland during the last 200 years, Geophys. Res. Lett., 23, 2235-2238, 1996.

Haan, D. and Raynaud, D.: Ice core record of CO variations during the last two millennia: atmospheric implications and chemical interactions within the Greenland ice, Tellus, 50B, 253-262, 1998.

Kato, S., Akimoto, H., Braunlich, M., Rockmann, T., and Brenninkmeijer, C. A. M.: Measurements of stable carbon and oxygen isotopic compositions of $\mathrm{CO}$ in automobile exhausts and ambient air from semi-urban Mainz, Germany, Geochem. J., 33, 7377, 1999a.

Kato, S., Akimoto, H., Rockmann, T., Braunlich, M., and Brenninkmeijer, C. A. M.: Stable isotopic compositions of carbon monoxide from biomass burning experiments, Atmos. Environ., 33, 4357-4362, 1999b.

Landais, A., Barnola, J. M., Kawamura, K., Caillon, N., Delmotte, M., Van Ommen, T., Dreyfus, G., Jouzel, J., Masson-Delmotte, V., Minster, B., Freitag, J., Leuenberger, M., Schwander, J., Huber, C., Etheridge, D., and Morgan, V.: Firn-air $\delta 15 \mathrm{~N}$ in modern polar sites and glacial-interglacial ice: a model-data mismatch during glacial periods in Antarctica?, Quaternary Sci. Rev., 25, 49-62, doi:10.1016/j.quascirev.2005.06.007, 2006.

Logan, J. A., Prather, M. J., Wofsy, S. C., and McElroy, M. B.: Tropospheric chemistry: a global perspective, J. Geophys. Res.Oc. Atm., 86, 7210-7254, 1981.

Lowe, D. C., Brenninkmeijer, C. A. M., Tyler, S. C., and
Dlugkencky, E. J.: Determination of the Isotopic Composition of Atmospheric Methane and Its Application in the Antarctic, J. Geophys. Res.-Atmos., 96, 15455-15467, 1991.

Mak, J. and Kra, G.: The isotopic composition of carbon monoxide at Montauk Point, Long Island, Chemosphere: Global Change Science 1, 1, 205-218, 1999.

Mak, J., Kra, G., Sandomenico, T., and Bergamaschi, P.: The seasonally varying isotopic composition of the sources of carbon monoxide at Barbados, West Indies, J. Geophys. Res.-Atmos., 108, 4635, doi:10.1029/2003jd003419, 2003.

Mak, J. E.: The Isotopes of Carbon Monoxide in the Free Troposphere and Their Implications to Atmospheric Chemistry, PhD Thesis, The University of California, San Diego and National Center for Atmospheric Research, 1992.

Mak, J. E. and Brenninkmeijer, C. A. M.: Compressed-Air Sample Technology for Isotopic Analysis of Atmospheric CarbonMonoxide, J. Atmos. Ocean Tech., 11, 425-431, 1994.

Mak, J. E., Brenninkmeijer, C. A. M., and Tamaresis, J.: Atmospheric ${ }^{14} \mathrm{CO}$ Observations and Their Use for Estimating Carbon Monoxide Removal Rates, J. Geophys. Res.-Atmos., 99, 2291522922, 1994.

Mak, J. E. and Brenninkmeijer, C. A. M.: Measurement of ${ }^{13} \mathrm{CO}$ and $\mathrm{C}^{18} \mathrm{O}$ in the free troposphere, J. Geophys. Res., 103, 19,347319,358, 1998.

Mak, J. E. and Yang, W.: Technique for Analysis of Air Samples for ${ }^{13} \mathrm{C}$ and ${ }^{18} \mathrm{O}$ in Carbon Monoxide via Continuous-Flow Isotope Ratio Mass Spectrometry, Anal. Chem., 70, 5159-5161, 1998.

Manning, M. R., Brenninkmeijer, C. A. M., and Allan, W.: Atmospheric carbon monoxide budget of the southern hemisphere: Implications of ${ }^{13} \mathrm{C} /{ }^{12} \mathrm{C}$ measurements, J. Geophys. Res.-Atmos., 102, 10673-10682, 1997.

Marlon, J. R., Bartlein, P. J., Carcaillet, C., Gavin, D. G., Harrison, S. P., Higuera, P. E., Joos, F., Power, M. J., and Prentice, I. C.: Climate and human influences on global biomass burning over the past two millennia, Nat. Geosci., 1, 697-702, doi:10.1038/ngeo313, 2008.

Merritt, D. A. and Hayes, J. M.: Factors controlling precision and accuracy in isotope ratio monitoring mass spectrometry, Anal. Chem., 66(14), 2336-2347, 1994.

Merritt, D. A., Hayes, J. M., and Marias, D. J. D.: Carbon Isotopic Analysis of Atmospheric Methane by Isotope-RatioMonitoring Gas-Chromatography Mass-Spectrometry, J. Geophys. Res.-Atmos., 100, 1317-1326, 1995.

Moss, R., Manning, M., Lowe, D., Ferretti, D., and Knobben, R.: Changes in atmospheric carbon monoxide in the pacific region, in: Preceedings of the Workshop on the Science of Atmospheric Trace Gases, edited by: Clarkson, T. S., 74-77, Natl. Inst. of Water and Atmos. Res., Wellington, New Zealand, 1998.

Murphy, D. M. and Koop, T.: Review of the vapour pressures of ice and supercooled water for atmospheric applications, Quart. J. Royal Met. Soc, 131, 1539-1565, 2005.

Neftel, A., Moor, E., Oeschger, H., and Stauffer, B.: Evidence from Polar Ice Cores for the Increase in Atmospheric $\mathrm{CO}_{2}$ in the Past 2 Centuries, Nature, 315, 45-47, 1985.

Rhee, T. S., Mak, J., Rockmann, T., and Brenninkmeijer, C. A. M.: Continuous-flow isotope analysis of the deuterium/hydrogen ratio in atmospheric hydrogen, Rapid Commun. Mass. Sp., 18, 299-306, doi:10.1002/rcm.1309, 2004.

Rice, A. L., Gotoh, A. A., Ajie, H. O., and Tyler, S. C.: High- 
precision continuous-flow measurement of $\delta^{13} \mathrm{C}$ and $\delta \mathrm{D}$ of atmospheric $\mathrm{CH}_{4}$, Anal. Chem., 73, 4104-4110, 2001.

Rockmann, T., Jöckel, P., Gros, V., Bräunlich, M., Possnert, G., and Brenninkmeijer, C. A. M.: Using ${ }^{14} \mathrm{C},{ }^{13} \mathrm{C},{ }^{18} \mathrm{O}$ and ${ }^{17} \mathrm{O}$ isotopic variations to provide insights into the high northern latitude surface CO inventory, Atmos. Chem. Phys., 2, 147-159, doi:10.5194/acp-2-147-2002, 2002.

Rockmann, T., Kaiser, J., Brenninkmeijer, C. A. M., and Brand, W. A.: Gas chromatography/isotope-ratio mass spectrometry method for high-precision position-dependent ${ }^{15} \mathrm{~N}$ and ${ }^{18} \mathrm{O}$ measurements of atmospheric nitrous oxide, Rapid Commun. Mass. Sp., 17, 1897-1908, doi:10.1002/rcm.1132, 2003.

Rudolph, J., Lowe, D. C., Martin, R. J., and Clarkson, T. S.: A novel method for compound specific determination of $\delta^{13} \mathrm{C}$ in volatile organic compounds at ppt levels in ambient air, Geophys. Res. Lett., 24, 659-662, 1997.

Santrock, J., Studley, S. A., and Hayes, J. M.: Isotopic Analyses Based on the Mass Spectrum of Carbon Dioxide, Anal. Chem., 57, 1444-1448, 1985.

Schütze, M.: Ein neues Oxidationsmittel für die quantitative Uberführung von Kohlenmonoxyd in Kohlendioxyd, Ein Beitrag zur Chemie des Jodpentoxids, Ber. Dtsch. Chem. Ges, 77b, 484487, 1949.

Schwander, J. and Stauffer, B.: Age Difference between Polar Ice and the Air Trapped in Its Bubbles, Nature, 311, 45-47, 1984.

Seiler, W.: Cycle of atmospheric CO, Tellus, 26, 116-135, 1974.

Smiley, W. G.: Note on a reagent for oxidation of carbon monoxide, Nucl. Sci. Abstr, 3, p. 391, 1949.
Stevens, C. M. and Krout, L.: Method of the determination of the carbon and of the oxygen isotopic composition of atmospheric carbon monoxide, Int. J. Mass Spectrom., 8, 265-275, 1972.

Stevens, C. M., Walling, D., Venters, A., Ross, L. E., Engelkem, A., and Krout, L.: Isotopic Composition of Atmospheric CarbonMonoxide, Earth Planet. Sc. Lett., 16, 147-165, 1972.

Stevens, C. M. and Wagner, A. F.: The Role of Isotope Fractionation Effects in Atmospheric Chemistry, Z. Naturforsch. A, 44, 376384, 1989.

Thompson, A. M.: The oxidizing capacity of the earth's atmosphere: probable past and future changes, Science, 256, 1157$1165,1992$.

Thompson, L. G., Mosley-Thompson, E., Davis, M. E., Lin, P. N., Henderson, K., and Mashiotta, T. A.: Tropical glacier and ice core evidence of climate change on annual to millennial time scales, Climatic Change, 59, 137-155, 2003.

Tsunogai, U., Nakagawa, F., Komatsu, D. D., and Gamo, T.: Stable Carbon and Oxygen Isotopic Analysis of Atmospheric Carbon Monoxide Using Continuous -Flow Isotope Ratio MS by Isotope Ratio Monitoring of CO, Anal. Chem., 74, 5659-5700, 2002.

Verschuren, D., Laird, K. R., and Cumming, B. F.: Rainfall and drought in equatorial east Africa during the past 1,100 years, $\mathrm{Na}$ ture, 403, 410-414, 2000.

Wang, Z. H.: Records of Concentration, ${ }^{13} \mathrm{C}$ and ${ }^{18} \mathrm{O}$ of Atmospheric $\mathrm{CO}$ in the past, Ph.D. thesis, Stony Brook University, USA, 2009. 